\title{
Sustainable oxidative cleavage of catechols for the synthesis of muconic acid and muconolactones including lignin upgrading
}

\author{
Florentin Coupé, ${ }^{\mathrm{a}, \mathrm{b}, \mathrm{c}}$ Laurène Petitjean, ${ }^{\mathrm{d}}$ Paul Anastas, ${ }^{{ }^{\mathrm{d}}}$ Frédéric Caijo, ${ }^{\mathrm{c}}$ Vincent Escande ${ }^{* \mathrm{~b}, \mathrm{c}}$ and \\ Christophe Darcel*a,
}

\author{
a. Univ Rennes, CNRS, ISCR (Institut des Sciences Chimiques de Rennes), UMR 6226, F-35000 Rennes, France \\ b. Labcom GreenCARE, Demeta-Université de Rennes 1-CNRS joint laboratory \\ c. Demeta S.A.S., 6 rue Pierre-Joseph Colin, 35000 Rennes France \\ d. Yale Center for Green Chemistry and Green Engineering, Yale University, 370 \\ Prospect Str., New Haven, CT 06511, USA
}

\begin{abstract}
Muconic acid and muconolactones are gaining high interest as platform molecules for the synthesis of a variety of compounds, especially in the domain of materials. Despite several technologies have been described for their synthesis, there is still a lack of performance, especially regarding green chemistry principles. In this study, we describe the development of an optimized catechol oxidative cleavage to muconic acid using performic acid in an intriguingly safe fashion. Common iron salts were used as catalysts to a level as low as 0.005 mol\%, for a maximum turnover number of 13200. Maximum muconic acid yield reached $84 \%$ after isolation by simple filtration. This procedure optimized on catechol was also efficient over a wide range of substituted catechols, providing the access to muconolactones in a domino reaction. Noticeably, biobased catechols produced by a proven technology of lignin depolymerization were cleaved into muconolactones of high functional value. Applying this supplementary cleavage step to lignin depolymerization catechols was thus an ultimate way to maximize the economical value created from lignin. In contrast with other studies, lignin was not only depolymerized, but depolymerization products were further transformed to take as much value from biomass as possible.
\end{abstract}

\section{Introduction}

Lignin is usually considered as a high potential biopolymer for the substitution of petroleum-based specialty chemicals. In particular, it has a high carbon content and is the only biomass-derived polymer characterized by a structure based on aromatic moieties. ${ }^{1}$ Even if it is found in abundant, nonedible biomass, its transformation should be efficient and comply with green chemistry principles.

However, lignin valorization still remains challenging, giving complex mixtures of products in poor yields. ${ }^{2-4}$ Lignin is extracted from lignocellulosic biomass using several processes. The preferred one is solvolysis, which preserves its structure the best. ${ }^{2}$ Lignin is then transformed via depolymerization, which allows the cleavage of several bond types, affording simple molecules, which can be afterwards further functionalized. $^{2}$ In 2014, Anastas et al. ${ }^{5}$ proposed a depolymerization process by hydrogenolysis using copperbased porous metal oxides (Cu-PMO). Starting from organosolv lignin extracted from Candlenut shells (Aleurites moluccana; Euphorbiaceae), the main depolymerization products were substituted catechols.

+ Footnotes relating to the title and/or authors should appear here. Electronic Supplementary Information (ESI) available: [details of any supplementary information available should be included here]. See DOI 10 1039/ $0 \quad 00000$
These catechols then open a new route to lignin upgrading, as they have relevant structures for further functionalizations. However, they might not have direct applications with specific properties. An interesting approach to valorize these monomers implies their cleavage to muconic acid derivatives. (Scheme 1) Indeed, muconic acid (MA), in its unsubstituted form, has caught a growing interest these last years as it has several potential applications. This lignin-based approach could therefore provide a sustainable source to oil-based industrial relevant chemicals. First, in the domain of materials, MA can serve as a precursor of monomers, like adipic acid, terephthalic acid and $\varepsilon$-caprolactam for the respective productions on Nylon 6-6, polyethylene terephthalate (PET) and Nylon $6 .^{6-8}$ MA can also directly be employed as a monomer for the design of new classes of polymers, either by polycondensation or by radical polymerization. ${ }^{9-11}$ Otherwise, MA can be converted into different compounds of interest such as trans-3-hexenedioic acid or cyclic ketones, especially cyclopentanone. ${ }^{10,12,13}$ Indeed, trans-3-hexenedioic acid was especially considered as a monomer for the synthesis of unsaturated Nylon 6-6. ${ }^{14}$ More noticeably, MA is known for its ability to undergo intramolecular cyclization, giving either muconolactones or dilactones. ${ }^{7,10}$ Moreover, muconolactones are reported to be formed spontaneously from a MA intermediate, depending on the catechol substrate structure. ${ }^{15}$ These lactones offer a complementary class of molecules to muconic acids and widen the field of application of catechols cleavage products. (Scheme 1) For example, muconolactones have a strong structure analogy with furanones, which have 
important functional applications, especially in the domain of

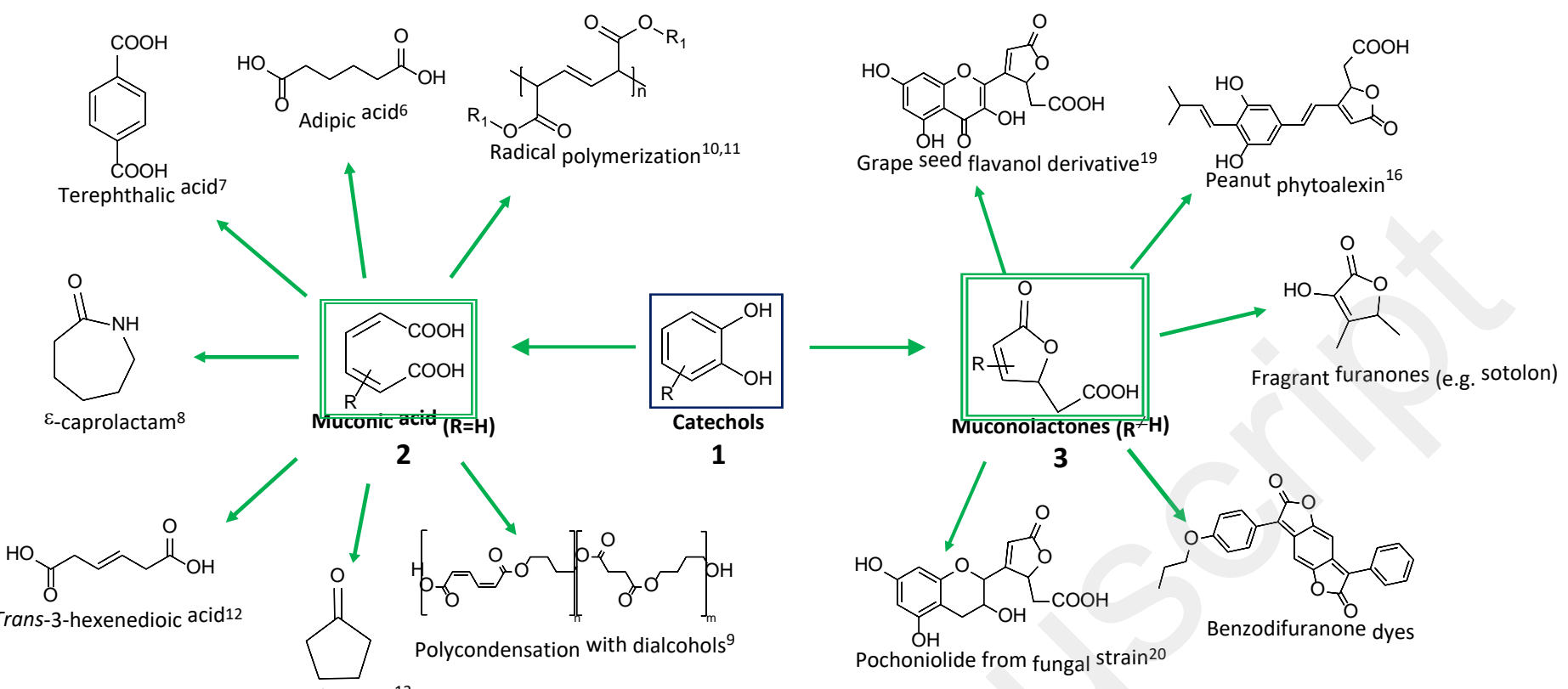

natural products. ${ }^{16-20}$ In definitive, MA can act as an important platform molecule. ${ }^{21,22}$

Scheme 1. Overview of selected applications for catechols cleavage products.

Current MA production methods are discriminated into two main approaches: biotechnological or chemical pathway. A large number of studies have been released on the MA production via microorganisms from a variety of substrates either of lignin type or not- and using several biological strains, mainly Pseudomonas putida, usually engineered. ${ }^{23-25}$ Even if these biochemical conversions can legitimately be considered as sustainable, they come along with some problematic aspects undesired for a large scale production: low concentration of the broth to prevent toxicity to microorganisms, as well as product extraction and purification difficulties. To get rid of these inconveniences, a preferred MA production goes through chemical conversion. This synthetic approach has been well described in the literature. In pioneering works, the catechol chemical cleavage reaction was designed in order to mimic the naturally occurring non-heme $\mathrm{Fe}(\mathrm{III})$ dioxygenases. ${ }^{26-30}$ Thus, several $\mathrm{Fe}(\mathrm{III})$ complexes were studied to describe the catechol intradiol cleavage, with molecular oxygen as the terminal oxidant. Among all these complexes, the one with tris(2-pyridylmethyl)amine as ligand expressed excellent activity (up to $85 \%$ MA yield, mixture of esters). ${ }^{31,32}$ Even though this aerobic route for the MA is very promising, it still has some disadvantages considering a potential industrial application (pressure of air, relatively high loading of expensive and non-recyclable catalyst and improvable MA yields). Another chemical route employed peracids, and essentially peracetic acid (PAA). Peracids in general are convenient reagents, as they are already widely produced and used at an industrial scale, as epoxidation reagents for example. ${ }^{33}$ Moreover their synthesis is simple, starting from cheap and abundant reagents, and creating almost no waste. In particular, Pandell described the catechol cleavage reaction with PAA using different conditions. ${ }^{34,35}$ To be efficient, the cleavage required sufficiently concentrated PAA, a low amount of water, the presence of a Fe(III) inorganic salt catalyst, and the slow addition of the catechol substrate. It also had the advantage of being carried out under standard/ambient conditions. Moreover, the obtained MA was insoluble in the reaction medium, which eased its isolation by simple filtration.

Therefore, we decided to make this promising technology the starting point of our study, to upgrade lignin depolymerization products into value-added compounds. In the current work, we report the use of simple iron salt-based catalysts for the oxidative cleavage of catechols, including bio-based catechols obtained from lignin depolymerization, by performic acid leading to substituted muconic acids derivatives and their related muconolactones.

\section{Experimental section}

\section{Typical procedure for catechol cleavage}

In a $25 \mathrm{~mL}$ round-bottomed flask, formic acid (10.40 g, 225 mmol) and $\mathrm{H}_{2} \mathrm{O}_{2}$ (50 wt\%, $3.06 \mathrm{~g}, 45.0 \mathrm{mmol}, 4.5$ equiv.) were stirred for $1 \mathrm{~h}$ at $20^{\circ} \mathrm{C}$ to pre-form performic acid in situ. Then $\left(\mathrm{NH}_{4}\right)_{2} \mathrm{Fe}\left(\mathrm{SO}_{4}\right)_{2} .6 \mathrm{H}_{2} \mathrm{O}(3.9 \mathrm{mg}, 0.1 \mathrm{~mol} \%)$ was dissolved in the pre-mix, and catechol 1a $(1.10 \mathrm{~g}, 10 \mathrm{mmol})$ dissolved in $4 \mathrm{~mL}$ of 
$\mathrm{HCOOH}$ was added in $4 \mathrm{~h} 30$ with a syringe pump. After the end of the addition, the mixture was stirred for $\mathbf{2 0}$ more hours to allow complete spontaneous peroxy decomposition (KI/starch test was negative at this time). Noticeably, NMR monitoring showed that no catechol remained in the reaction mixture only $1 \mathrm{~h}$ after the end of the addition. The obtained insoluble muconic acid 2a was then filtered off, washed with a minimum amount of $\mathrm{H}_{2} \mathrm{O}$, and dried in a desiccator $\left(\mathrm{P}_{2} \mathrm{O}_{5}\right)$ (light grey solid, $1.19 \mathrm{~g}, 84 \%$ isolated yield). Purity was checked by ${ }^{1} \mathrm{H}$ NMR $\left(\mathrm{DMSO}-d_{6}\right)$. In a separate experiment, filtrate concentration followed by acetone washing allowed to recover $4 \%$ more muconic acid with $90 \%$ purity.

\section{Representative procedure for substituted catechol cleavage, protocatechuic acid}

In a $25 \mathrm{~mL}$ round-bottomed flask, formic acid (5.20 g, 112 mmol) and $\mathrm{H}_{2} \mathrm{O}_{2}(50 \mathrm{wt} \%, 1.53 \mathrm{~g}, 22.5 \mathrm{mmol}$ ) were stirred for 1 $\mathrm{h}$ at $20{ }^{\circ} \mathrm{C}$ to pre-form performic acid in situ. Then $\left(\mathrm{NH}_{4}\right)_{2} \mathrm{Fe}\left(\mathrm{SO}_{4}\right)_{2} .6 \mathrm{H}_{2} \mathrm{O}(2.0 \mathrm{mg}, 0.1 \mathrm{~mol} \%)$ was dissolved in the pre-mix, and protocatechuic acid $1 \mathrm{~h}(0.77 \mathrm{~g}, 5.0 \mathrm{mmol})$ was added portionwise in $2 \mathrm{~h}$ (note that depending on the substrate nature and solubility in $\mathrm{HCOOH}$, it was either added portionwise or in solution in $\mathrm{HCOOH}$ ). After the end of the addition, the mixture was stirred for $\mathbf{2 0}$ more hours, until all peroxides were spontaneously decomposed (KI/starch test negative). The medium was then concentrated in vacuo to leave 4-carboxyl-5-carboxymethyl-2-furanone $3 \mathrm{~h}$ as a grey solid residue $\left(0.697 \mathrm{~g}, 68 \%\right.$ at purity estimated at $90 \%$ by ${ }^{1} \mathrm{H}$ NMR). Further purification was achieved by basic/acidic successive washings and recrystallization.

\section{Results and discussions}

\section{Development of the catalytic process on catechol}

Nature of the oxidizing mixture. The most employed peracids in organic synthesis are meta-chloroperbenzoic acid ( $m$-CPBA) and peracetic acid (PAA). Despite this, only PAA has been extensively studied in the catechol cleavage reaction in the literature, probably because it is a cheap, and readily available reagent. $m$-CPBA however was not selected as a potential candidate as it poorly fulfils green chemistry requirements. In a first approach, PAA was employed as the oxidant from two different sources: either from its commercial form (35 wt\% in $\mathrm{AcOH})$, or from an in situ preparation from $\mathrm{AcOH}$ and $\mathrm{H}_{2} \mathrm{O}_{2}(1: 1$ molar ratio) catalyzed by 1 wt\% of $\mathrm{H}_{2} \mathrm{SO}_{4}$ (Table 1 , entries 1-5). Noticeably, 4.5 equivalents of oxidant were employed, which corresponded to an excess of only 2.5 equivalents, as previously reported in mechanistic considerations affirming that 2 equivalents were required. ${ }^{36,37}$ In the case of in situ prepared $\mathrm{PAA}$, the number of equivalents was determined by the $\mathrm{H}_{2} \mathrm{O}_{2}$ total added amount, as it regenerates PAA while it is consumed upon catechol addition. As mentioned in previous contributions, $^{35,37}$ the in situ $\mathrm{Fe}$ (III)-catecholate complex formed in a first step was then oxidized with PFA giving an $o$ quinone intermediate. In the presence of the PFA, this latter led to muconic acid through a possible cyclic muconic anhydride. Noticeably, such intermediates were not observed in the present conditions, which may be due to their low stability in the reaction conditions.

Both PAA sources -commercial or in situ prepared- gave similar results (25\% and $20 \% \mathrm{MA} 2 \mathrm{a}$ isolated yields, respectively). Considering that commercially available PAA is a solution of PAA in $\mathrm{AcOH}$, the in situ prepared PAA is actually a mixture of AcOH, PAA, $\mathrm{H}_{2} \mathrm{O}_{2}$ and $\mathrm{H}_{2} \mathrm{O}$ in an equilibrium state. ${ }^{33,38}$ So, to displace the initial equilibrium towards the formation of $\mathrm{PAA}$, a AcOH: $\mathrm{H}_{2} \mathrm{O}_{2}$ ratio of $10: 1$ was tested (Table 1 , entry 2 ). Thus, the MA yield slightly increased to $34 \%$. Also, this result can attest that diluting water brought by the $\mathrm{H}_{2} \mathrm{O}_{2}$ solution has a beneficial effect on the reaction, as previously reported. ${ }^{35}$ To confirm this, and to bring even less $\mathrm{H}_{2} \mathrm{O}$ in the mixture, a more concentrated $\mathrm{H}_{2} \mathrm{O}_{2}$ solution ( 50 wt\% in $\mathrm{H}_{2} \mathrm{O}$ ) was used (Table 1, entries 3-4). Surprisingly, the associated yields were not better than with $\mathrm{H}_{2} \mathrm{O}_{2} 30$ wt\%, and even dropped to $9 \%$ with a $\mathrm{AcOH}: \mathrm{H}_{2} \mathrm{O}_{2}$ ratio of $1: 1$. This strategy was thus not completely satisfying for a yield increase.

On another hand, it is described that performic acid (PFA) is a much stronger oxidizer than PAA. ${ }^{33}$ Astonishingly, almost no studies employed this peracid in the catechol cleavage reaction. ${ }^{39}$ In this context, we decided to test its efficiency in the target reaction. Despite the appearances, PFA, when handled properly, is not hazardous. ${ }^{33,40,41}$ Especially, when prepared in situ, it doesn't require any intermediate storage or transportation. Indeed, PFA can be conveniently prepared by simple mixing of commercial formic acid and hydrogen peroxide solution, in a short reaction time, without the need for any acid catalyst. ${ }^{42,43}$ The proportions of formic acid and hydrogen peroxide only need to be set up properly to avoid to have a mixture composition in the explosivity range of the $\mathrm{HCOOH}: \mathrm{H}_{2} \mathrm{O}_{2}: \mathrm{H}_{2} \mathrm{O}$ ternary system (see ESI, Fig. S1). ${ }^{33}$ Moreover, PFA decomposes slowly, so that any left residue after the cleavage reaction would be decomposed spontaneously, leaving no hazardous peroxide species in the reaction mixture. ${ }^{42,43}$ Finally, formic acid can be easily obtained from sustainable sources. ${ }^{44}$

The in situ generated PFA was evaluated using the same reaction conditions than the ones used for PAA. Based on the best result obtained with in situ prepared PAA, we prepared PFA with a $\mathrm{HCOOH}: \mathrm{H}_{2} \mathrm{O}_{2} 50$ wt\% 10:1 mixture (Table 1, entry 6). Using this medium, the MA isolated yield increased up to $80 \%$. PFA prepared in these conditions was thus considered as being a very powerful oxidant for the reaction. 
Table 1. Assessment of different oxidizing mixtures.

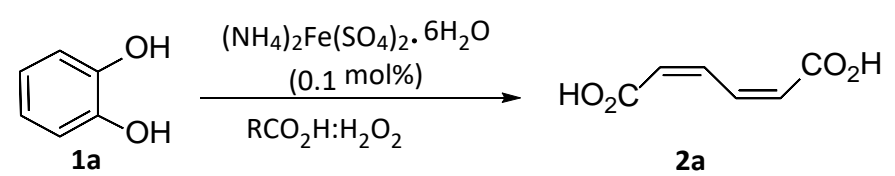

Conditions: $10 \mathrm{mmol}$ catechol $1 \mathrm{la}$ added in $4.5 \mathrm{~h}, 4.5$ equiv. $\mathrm{H}_{2} \mathrm{O}_{2}, 20{ }^{\circ} \mathrm{C}, 0.1 \mathrm{~mol} \%$ $\left(\mathrm{NH}_{4}\right)_{2} \mathrm{Fe}\left(\mathrm{SO}_{4}\right)_{2} \cdot 6 \mathrm{H}_{2} \mathrm{O}$. ${ }^{a}$ When $\mathrm{AcOH}$ was used, the peracid synthesis was performed in $24 \mathrm{~h}$ at $20{ }^{\circ} \mathrm{C}$, catalyzed by $1 \mathrm{wt} \% \mathrm{H}_{2} \mathrm{SO}_{4} .{ }^{b}$ Commercial peracetic acid solution, $35 \mathrm{wt} \%$ in $\mathrm{AcOH} .{ }^{c}$ Isolated yield.

Nature of the metal catalyst. The catechol cleavage by peracids is a reaction allowed by a catalyst species. Many metals have been tested by the past, and simple Fe salts have been described to have among the best activities. ${ }^{35}$ Thus, the activity of several

metal salts was evaluated with the PFA system.

From Table S1 (ESI), the Fe-based catalysts can be easily discriminated from the other tested metals, for which the MA isolated yields did not excess $35 \%$. A notable exception is $\mathrm{Fe}_{2} \mathrm{O}_{3}$, which was not soluble enough in the reaction medium to act as a catalyst ( $5 \%$ isolated yield). Even more interestingly, as seen in Table 2, entries 3-10, all Fe salts gave MA with close yields at high catalytic loading ( $0.1 \mathrm{~mol} \%, 73 \%$ to $80 \%$ yields). This is in accordance with previous observations on Fe(III) species. ${ }^{34}$ Furthermore, the initial Fe oxidation state had no influence (0, II, or III) on the efficiency, showing that performic acid is able to oxidize Fe to a higher active oxidation state. This is, to the best of our knowledge, the first report of the use of Fe at lower oxidation states than +III in a peracid-based system.

Optimization of the PFA oxidizing mixture. After having evaluated the influence of the peracid and the metal catalyst natures, complementary experiments were carried out to better understand the influence of the $\mathrm{HCOOH}: \mathrm{H}_{2} \mathrm{O}_{2}$ ratio, and to potentially improve the MA yield. $\mathrm{HCOOH}: \mathrm{H}_{2} \mathrm{O}_{2} 50$ wt\% 10:1 was first selected, as being the most promising one. To verify this, $\mathrm{H}_{2} \mathrm{O}_{2} 30$ wt\% was also tested with a $\mathrm{HCOOH}: \mathrm{H}_{2} \mathrm{O}_{2} \quad 1: 1$ ratio, and led to lower yield, even if it overclassed all results obtained with PAA. In this continuity, $\mathrm{H}_{2} \mathrm{O}_{2} 50$ wt\% was used as the unique $\mathrm{H}_{2} \mathrm{O}_{2}$ source. Then, to verify the effect of the

\begin{tabular}{|c|c|c|c|}
\hline Entry & Catalyst & $\begin{array}{l}\text { Fe loading } \\
\text { (mol\%) }\end{array}$ & $\begin{array}{l}\text { Yield 2a } \\
(\%)^{b}\end{array}$ \\
\hline 1 & Without Catalyst & / & 3 \\
\hline 2 & $\mathrm{Fe}_{2} \mathrm{O}_{3}$ & 0.1 & 5 \\
\hline 3 & $\mathrm{Fe}(\mathrm{acac})_{3}$ & 0.1 & 73 \\
\hline 4 & $\mathrm{~K}_{3}\left[\left(\mathrm{C}_{2} \mathrm{O}_{4}\right)_{3} \mathrm{Fe}\right] \cdot 3 \mathrm{H}_{2} \mathrm{O}$ & 0.1 & 75 \\
\hline 5 & $\mathrm{FeCl}_{2}$ & 0.1 & 76 \\
\hline 6 & $\mathrm{FeCl}_{3}$, anhydrous & 0.1 & 77 \\
\hline 7 & Ferric ammonium citrate & 0.1 & 78 \\
\hline 8 & $\mathrm{Fe}(\mathrm{CO})_{5}$ & 0.1 & 78 \\
\hline 9 & $\left(\mathrm{NH}_{4}\right)_{2} \mathrm{Fe}\left(\mathrm{SO}_{4}\right)_{2} \cdot 6 \mathrm{H}_{2} \mathrm{O}$ & 0.1 & 80 \\
\hline 10 & Fe powder & 0.1 & 80 \\
\hline 11 & $\mathrm{Fe}(\mathrm{acac})_{3}$ & 0.01 & 45 \\
\hline 12 & $\mathrm{~K}_{3}\left[\left(\mathrm{C}_{2} \mathrm{O}_{4}\right)_{3} \mathrm{Fe}\right] \cdot 3 \mathrm{H}_{2} \mathrm{O}$ & 0.01 & 68 \\
\hline \multirow{2}{*}{\multicolumn{2}{|c|}{$\begin{array}{l}13 \quad \mathrm{FeCl}_{3} \text {, anhydrous } \\
4_{4} \text { J. } \mathrm{NqK}_{3}\left[\mathrm{CO}_{2} \mathrm{O}_{4}\right)_{3}^{12} \mathrm{Fe} .3 \mathrm{H}_{2}^{1} \mathrm{O}^{3}\end{array}$}} & 0.01 & 68 \\
\hline & & 0.005 & 49 \\
\hline 15 & Ferric ammonium citrate & 0.005 & 49 \\
\hline 16 & $\mathrm{FeCl}_{3}$, anhydrous & 0.005 & 61 \\
\hline 17 & $\left(\mathrm{NH}_{4}\right)_{2} \mathrm{Fe}\left(\mathrm{SO}_{4}\right)_{2} \cdot 6 \mathrm{H}_{2} \mathrm{O}$ & $0.005^{c}$ & 66 \\
\hline 18 & $\left(\mathrm{NH}_{4}\right)_{2} \mathrm{Fe}\left(\mathrm{SO}_{4}\right)_{2} \cdot 6 \mathrm{H}_{2} \mathrm{O}^{a}$ & $0.0025^{d}$ & 10 \\
\hline
\end{tabular}

$\mathrm{HCOOH}: \mathrm{H}_{2} \mathrm{O}_{2}$ ratio

\begin{tabular}{lllll} 
Entry & Acid $^{a}$ & $\begin{array}{l}\mathrm{H}_{2} \mathrm{O}_{2} \text { strength } \\
(\text { wt\%) }\end{array}$ & $\begin{array}{l}\text { Acid: } \mathrm{H}_{2} \mathrm{O}_{2} \\
\text { molar ratio }\end{array}$ & $\begin{array}{l}\text { Yield }^{c} \\
\text { 2a (\%) }\end{array}$ \\
\hline 1 & $\mathrm{AcOH}$ & 30 & 1 & 25 \\
2 & $\mathrm{AcOH}$ & 30 & 10 & 34 \\
3 & $\mathrm{AcOH}$ & 50 & 1 & 9 \\
4 & $\mathrm{AcOH}$ & 50 & 10 & 31 \\
5 & $\mathrm{PAA}$ & $/$ & $/$ & 20 \\
6 & $\mathrm{HCOOH}$ & 50 & 10 & 80
\end{tabular}

Table 2. Catechol 1a cleavage - Screening of different Fe salts as catalysts, at different catalytic loadings.

Conditions: 10 mmol catechol 1 a added in $4.5 \mathrm{~h}, 4.5$ equiv. $\mathrm{H}_{2} \mathrm{O}_{2}$ (50 wt\%), $\mathrm{HCOOH}: \mathrm{H}_{2} \mathrm{O}_{2}$ 10:1 molar ratio, $20{ }^{\circ} \mathrm{C}$. ${ }^{a}$ Reaction performed in duplicate gave the same result. ${ }^{b}$ Isolated yield. ${ }^{c} 50 \mathrm{ppm} \mathrm{Fe} .^{d} 25 \mathrm{ppm} \mathrm{Fe}$.

other mixtures were tested (Fig. 1). The lowest experimented ratio was $2.7: 1$, which was slightly higher to the upper limit of the explosivity range of the $\mathrm{HCOOH}: \mathrm{H}_{2} \mathrm{O}_{2}: \mathrm{H}_{2} \mathrm{O}$ ternary system. The $\mathrm{HCOOH}: \mathrm{H}_{2} \mathrm{O}_{2}$ 1:1 ratio was not tested due to this constraint (see ESI, Fig. S1). ${ }^{33}$

This 2.7:1 ratio gave slightly worse results, with a $73 \%$ muconic acid isolated yield (Fig. 1). Finally, the intermediate ratio 5:1 was also applied, and corresponded to the best obtained yield of $84 \%$. This can be explained as it may be an optimum value between pushing the equilibrium towards the PFA formation and a too dilute medium due to a too large excess of $\mathrm{HCOOH}$.

The PFA solution formed with this ratio is clearly outside of the explosivity range (see ESI, Fig.S1) ${ }^{33}$ and is thus a safer oxidizing mixture. Moreover, using a lower excess of $\mathrm{HCOOH}$ than in the 10:1 mixture is beneficial in terms of mass engaged in the reaction, giving better metrics values such for mass intensity (see ESI, Table S3 for green chemistry metrics calculation).

Catalytic loading. In a first approach, a standard low value of 0.1 mol\% catalyst loading was applied to evaluate the best catalysts. At this catalytic loading, the obtained MA yields ranged from $73 \%$ to $84 \%$, giving turnover number (TON) values varying between $730-840$. On this basis, the Fe species were tested with a tenfold decrease in catalytic loading (Table 2, entries 11-13). However, even this catalytic loading value was too high to discriminate the different salts. Only $\mathrm{Fe}(\mathrm{acac})_{3}$ showed a lower activity (68\%, TON 6800). Then, the catalytic loading value was further halved to $0.005 \mathrm{~mol} \%$ (i.e. $50 \mathrm{ppm}$ Fe) (Table 2, entries 14-17). Indeed, most of the salts led to a MA yield below $60 \%$. Remarkably, $\left(\mathrm{NH}_{4}\right)_{2} \mathrm{Fe}\left(\mathrm{SO}_{4}\right)_{2} \cdot 6 \mathrm{H}_{2} \mathrm{O}$ still provided a decent MA yield of $66 \%$, with an associated TON of 13200. $\left(\mathrm{NH}_{4}\right)_{2} \mathrm{Fe}\left(\mathrm{SO}_{4}\right)_{2} \cdot 6 \mathrm{H}_{2} \mathrm{O}$ was then tested on an even lower catalytic loading $(0.0025 \mathrm{~mol} \%$ i.e. $25 \mathrm{ppm})$, but the MA yield significantly dropped to $10 \%$ (Table 2 , entry 18 ). Thus, the optimal catalytic loading value was of $0.01 \mathrm{~mol} \%$, regardless of 
the Fe salt employed, but with a slight preference for $\left(\mathrm{NH}_{4}\right)_{2} \mathrm{Fe}\left(\mathrm{SO}_{4}\right)_{2} \cdot 6 \mathrm{H}_{2} \mathrm{O}$ as it was the most active at very low catalytic loadings.

Figure 1. Optimization of the $\mathrm{HCOOH}: \mathrm{H}_{2} \mathrm{O}_{2}$ ratio. Conditions: $10 \mathrm{mmol}$ catechol

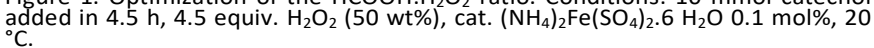

An optimized procedure for the peracid-based catechol cleavage was thus designed with in situ preformed performic acid, synthetized with pure $\mathrm{HCOOH}$ and $\mathrm{H}_{2} \mathrm{O}_{2} 50 \mathrm{wt} \%$. The best conditions to perform the reaction were a $\mathrm{HCOOH}: \mathrm{H}_{2} \mathrm{O}_{2} \quad 5: 1$ ratio, using $0.01 \mathrm{~mol} \%$ of a Fe inorganic species as catalyst. The cleavage was carried out at $20{ }^{\circ} \mathrm{C}$ and required the slow addition of the catechol substrate over a $4 \mathrm{~h} 30$ period. In these conditions, the MA $2 a$ isolated yield reached its maximum value of $84 \%$.

\section{Feasibility of the process on substituted catechols}

When we first developed this peracid-based technology for the catechol cleavage, not only we desired a green, reliable process for the synthesis of MA, but we also had in mind its potential

applicability on substituted catechols. We then decided to screen the scope of substituted catechol substrates. Figure 2 gives an overview of all obtained structures from these catechol cleavages. The main difference with catechol cleavage resided in the nature of the obtained products. While catecho cleavage led specifically to the formation of MA $\mathbf{2 a}$, almost all substituted catechols $\mathbf{1}$ furnished muconolactone cyclic structures 3. They resulted from an intramolecular heteroMichael addition of the muconic acid cleavage product, as already described. ${ }^{15}$ This cyclization reaction may also be favoured by the very high acidity of the medium. The susceptibility of the muconic acid intermediate to evolve towards the muconolactone structure also relied on its substituent steric hindrance. Indeed, 4-methylcatechol 1b, 4chlorocatechol 1c and 3-methoxycatechol 1d led to "free" muconic acid derivatives $\mathbf{2} \mathbf{b}$ - $\mathbf{d}$ after the cleavage reaction, as minor products (with yields up to $34 \%$ ). Indeed, for each substrate, the produced muconic acid can evolve in two different muconolactones, but only one is observed, as

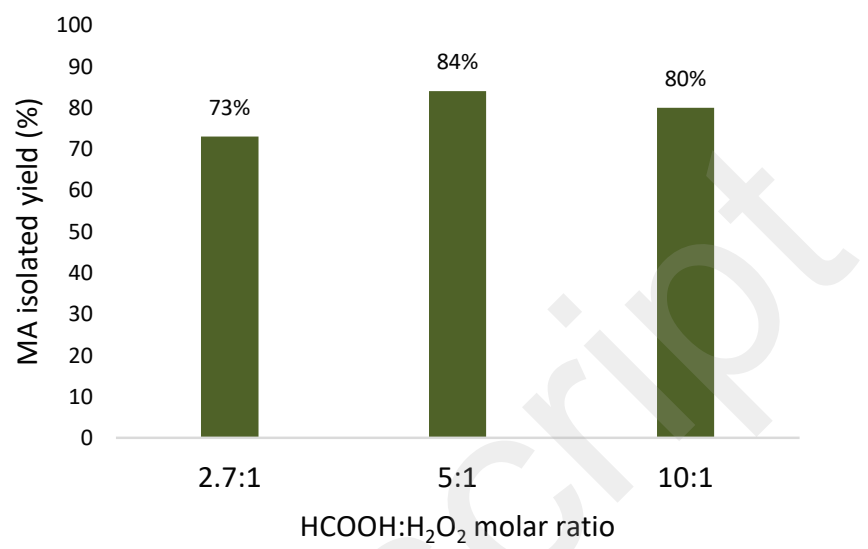

previously reported. ${ }^{15}$ However, starting from 4-nitrocatechol $\mathbf{1 e}$, the conversion was incomplete $(85 \%)$ and only a mixture of isomers of 3-nitro-2,4-hexadienedioic acid $2 \mathbf{e}$ was obtained (39\%), and no muconolactone was observed, possibly due to the $-\mathrm{NO}_{2}$ strong electrophilic character which inhibited the cyclization. By contrast, catechols bearing electronwithdrawing group like caffeic acid $\mathbf{1 g}$ and protocatechuic acid $\mathbf{1 h}$, after cleavage, led to muconolactones $\mathbf{3 g}$ and $\mathbf{3 h}$ in moderate yields (58\% and $68 \%$, respectively). Thus, the electronic properties of the substituent have an influence on the obtained yield: with catechols bearing electron-donating substituents (e.g. 1b, 1d, 1f), the corresponding muconolactones $\mathbf{3 b}, \mathbf{3 d}$ and $\mathbf{3} \mathbf{f}$ were obtained in variable yields (5-71\%). Starting from 4-chlorocatechol 1c, a mixture of two muconolactones $\mathbf{3 c}-\mathbf{i}$ and $3 \mathbf{c}$-ii was obtained. Among all the tested substrates, 4-cyanocatechol did not react. Finally, 3,5Di-tert-butylcatechol 1f, a reference substituted catechol, gave the muconolactone $3 \mathbf{f}$ in $37 \%$ yield.

Thus, in the case of substituted catechols, the oxidative cleavage went through muconic acids which could then evolve

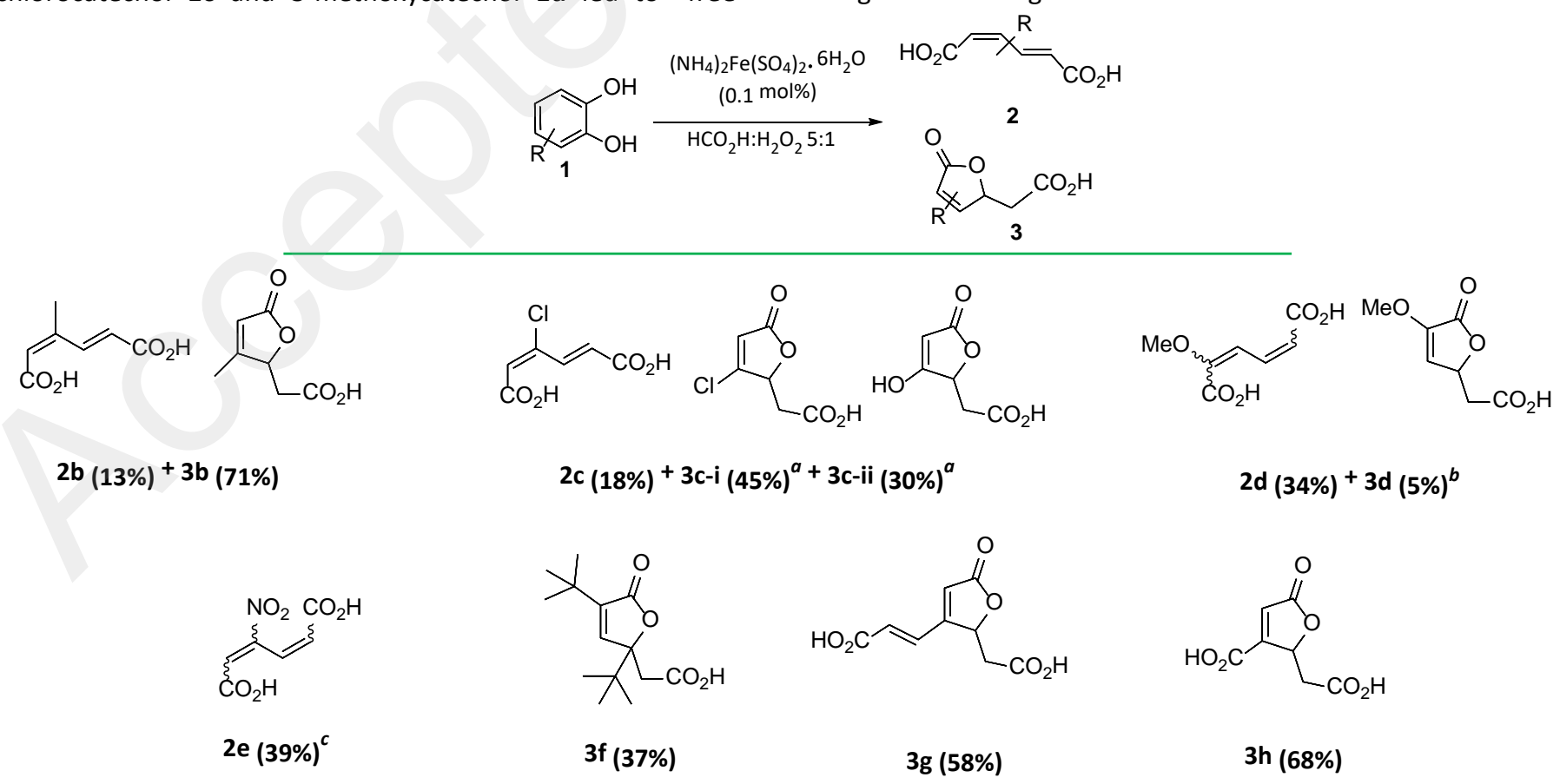


through a hetero-Michael intramolecular addition leading to the cyclic muconolactone, highlighting the steric and stereoelectronic effect of the substituents on the cyclisation susceptibility. Such a reactivity is consistent with what has already been described. ${ }^{15}$

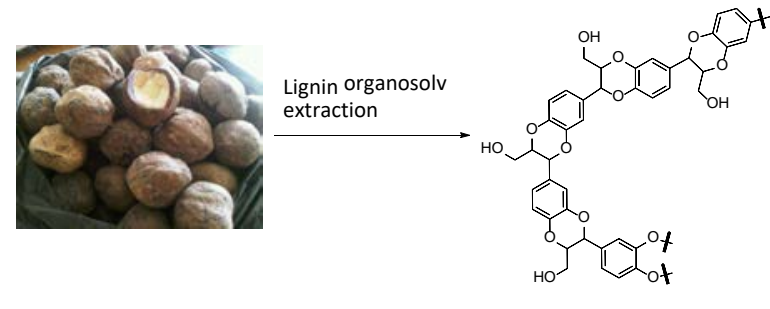

Candlenut shells
C-lignin

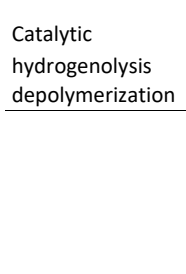

Catechols

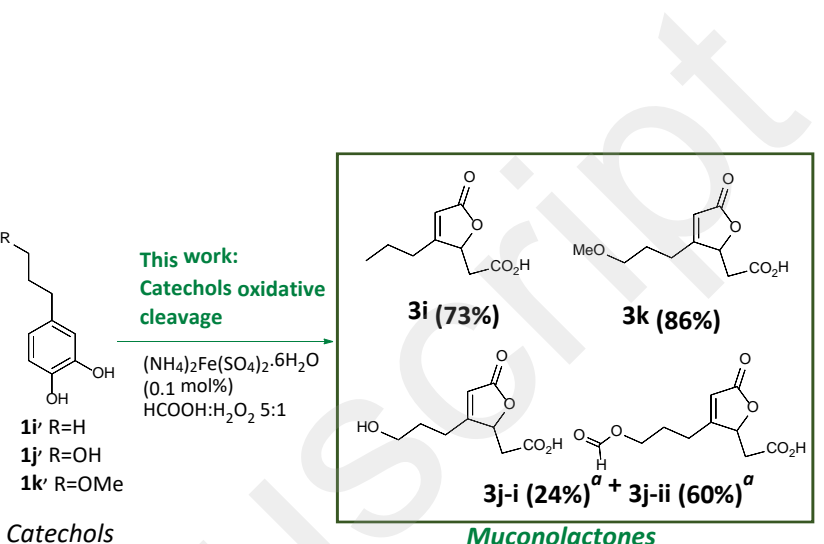

Muconolactones

Figure 3. Complete sequence used to obtain muconolactones from biomass, passing through lignin. Percentages are isolated yields. ${ }^{a} 3 \mathrm{j}$-ii was obtained as a mixture with $3 \mathrm{j}-\mathrm{i}$ and resulted from the formylation of $3 \mathrm{j}-\mathrm{i}$ in the reaction conditions (molar ratio formylated:non formylated 8:3).

\section{Application to catechols from C-lignin}

After having proven the efficiency of our PFA-based technology on substituted catechols, we decided to look deeper into sustainable sources of catechols. Indeed, the main catechol production comes from the petroleum industry, even if its production from biomass is emerging, for example from biobased ferulic acid. ${ }^{45}$ On another hand, guaiacol, which has a very similar structure to catechol, is often reported as a major lignin depolymerization product. $^{2}$ The developed ironcatalyzed cleavage process was thus evaluated with commercial guaiacol. Unfortunately, only small amounts of MA 2a were isolated in this case (up to $25 \%$ ). The presence of a methyl on one of the hydroxy groups impeded the reaction by hindering the formation of the complex with the Fe(III) catalyst. Nonetheless, guaiacol demethylation could be accounted as a route to biobased catechol. ${ }^{46-48}$ In 2014, Anastas et al. reported the formation of four substituted catechols from the depolymerization of lignin sourced from candlenut shells, using hydrogenolysis catalyzed by Cu-PMOs. ${ }^{5}$ Recent insights revealed that the formation of catechols in these conditions was not exclusively due to the employed process, but the nature of the starting biomass has a preponderant role. Indeed, for decades, lignin was thought to be a polymer based exclusively on paracoumaryl alcohol $(\mathrm{H})$, coniferyl alcohol (G) and sinapyl alcohol (S) units. However, in 2012, Ralph et al. reported the existence of a different lignin type, based on caffeyl alcohol (C) units, first found in vanilla seeds. ${ }^{49}$ Thereafter, lignin from "classical" biomass was renamed GS-lignin, whereas this newly discovered lignin was designated as C-lignin. C-lignin from vanilla, upon depolymerization, has been shown to give back catechol moieties through benzodioxane linkage breaking. ${ }^{50,51}$ Then Clignin was found to be present in high amounts in candlenut shells, explaining the formation of catechols from its lignin depolymerization. ${ }^{52}$ Even if C-lignin appears to be much less abundant than GS-lignin, being restricted to specific biomass sources, it still counts as an important feedstock, as candlenut is a crop developed for its oil, transformed into biodiesel. Another relevant C-lignin source may come from castor bean shells, ${ }^{52,53}$ which are grown for their highly-containing ricinoleic acid oil, especially used for the manufacture of Polyamide $11 .{ }^{54}$

Once the process optimized on catechol and screened on different petroleum-based substituted catechols, it was then applied to catechols obtained from lignin depolymerization. We decided to work on lignin issued from candlenut shells, being rich in C-lignin, giving, via hydrogenolysis depolymerization, alkyl-substituted catechols which are good candidates for our iron-catalysed cleavage reaction.

First, the cleavage was performed on the isolated catechols, using previously developed conditions $\left(\mathrm{HCOOH}: \mathrm{H}_{2} \mathrm{O}_{2} 50\right.$ wt\% $\left.5: 1,\left(\mathrm{NH}_{4}\right)_{2} \mathrm{Fe}\left(\mathrm{SO}_{4}\right)_{2} \cdot 6 \mathrm{H}_{2} \mathrm{O} 0.1 \mathrm{~mol} \%\right)$. As previously observed, these catechols $\mathbf{1} \mathbf{i}-\mathbf{k}$ evolved specifically to the muconolactone derivatives 3i-k, with high yields in isolated forms (Figure 3, $73 \%$ to $86 \%$ ). Notably, no secondary products were observed, except in the case of 4-(3-hydroxypropyl)catechol $\mathbf{1} \mathbf{j}$, whose hydroxy lateral group was formylated at $71 \%$. The cleavage was also tested directly on lignin depolymerization oil, and the expected products were observed, with no catechols remaining (ratio 3i:3j-i:3j-ii:3k of 7:2:5:3). 


\section{Conclusions}

A sustainable process was designed to allow the efficient cleavage of catechol substrates. First, it allowed the manufacture of muconic acid from catechol in high yields, up to $84 \%$. Performic acid was employed as the oxidant, synthetized in situ from formic acid and $\mathrm{H}_{2} \mathrm{O}_{2}$. In these conditions, formic acid played the role of the solvent, so that no additional solvent was required. Moreover, product isolation was performed by simple filtration. All these aspects make the process highly interesting in terms of mass intensity (15.6 $\mathrm{kg} / \mathrm{kg}_{\mathrm{MA}}$, see ESI, Table S3). Furthermore, this also impacts the $E$ factor value positively, determined at 2.0, which is a very low value considering that the process falls into the field of fine chemistry. On the other hand, performic acid was handled in appropriate conditions, so that there were no safety issues using it. Even more, the terminal oxidant was actually $\mathrm{H}_{2} \mathrm{O}_{2}$, which is a benign oxidant. Also, performic acid, upon reaction, gave back formic acid, which could therefore be recovered, for example by extractive distillation regarding an industrial application. ${ }^{55,56}$ Thus, the only significant waste was water, which was brought by the $\mathrm{H}_{2} \mathrm{O}_{2}$ solution. The catalyst used was a simple inorganic iron salt. Beyond its use in very low quantities, iron is a nontoxic, Earth-abundant element, with no risk of ore depletion even at long term. Moreover, there was no need to add an elaborated, expansive organic ligand to make it active in the cleavage reaction. Finally, the process was highly efficient to open the route to muconolactone compounds. Especially, catechols obtained from lignin depolymerization were converted into original muconolactones with good yields $(>70 \%)$. They represent a promising class of intermediates towards the synthesis of compounds of interest, while allowing the valorization of lignin depolymerization products in an efficient fashion.

\section{Conflicts of interest}

There are no conflicts to declare.

\section{Acknowledgements}

We thank the Universite de Rennes 1 , the Centre National de la Recherche Scientifique (CNRS), the Région Bretagne, and the ANR labcom program (17-LCV2-0009-01). F. C. thanks the ANRT for a CIFRE PhD grant and Rennes Metropole council for a mobility grant.

\section{Notes and references}

1 Y. Lu, Y.-C. Lu, H.-Q. Hu, F.-J. Xie, X.-Y. Wei and X. Fan, J. Spectrosc., 2017, 115.

2 W. Schutyser, T. Renders, S. V. den Bosch, S.-F. Koelewijn, G. T. Beckham and B. F. Sels, Chem. Soc. Rev., 2018, 47, 852-908.

3 L. Cao, I. K. M. Yu, Y. Liu, X. Ruan, D. C. W. Tsang, A. J. Hunt, Y. S. Ok, H. Song and S. Zhang, Bioresour. Technol., 2018, 269, 465-475.

4 C. Liu, S. Wu, H. Zhang and R. Xiao, Fuel Proc. Technol., 2019, 191, 181-201.
5 K. Barta, G. R. Warner, E. S. Beach and P. T. Anastas, Green Chem., 2014, 16 191-196.

6 D. R. Vardon, N. A. Rorrer, D. Salvachúa, A. E. Settle, C. W. Johnson, M. J. Menart, N. S. Cleveland, P. N. Ciesielski, K. X. Steirer, J. R. Dorgan and G. T. Beckham, Green Chem., 2016, 18, 3397-3413.

7 J. M. Carraher, T. Pfennig, R. G. Rao, B. H. Shanks and J. P. Tessonnier, Green Chem., 2017, 19, 3042-3050.

8 L. Coudray, J. W. Frost and D. Schweitzer, Amyris, Inc., US 2013/0085255A1, 2013.

9 N. A. Rorrer, J. R. Dorgan, D. R. Vardon, C. R. Martinez, Y. Yang and G. T. Beckham, ACS Sust. Chem. Eng., 2016, 4, 6867-6876.

10 J. L. Milan, M. Mang and C. Ozmer-Al, Myriant Corp., Wo 2016/069411A1, 2016.

11 G. Quintens, J. H. Vrijsen, P. Adriaensens, D. Vanderzande and T. Junkers, Polym. Chem., 2019, 10, 5555-5563.

12 J. E. Matthiesen, J. M. Carraher, M. Vasiliu, D. A. Dixon and J. P. Tessonnier, ACS Sust. Chem. Eng., 2016, 4, 3575-3585.

13 J. S. Pierre, L. Duran and A. V. Heiningen, J. Anal. Appl. Pyrol., 2015, 113, 591598.

14 M. Suastegui, J. E. Matthiesen, J. M. Carraher, N. Hernandez, N. R. Quiroz, A Okerlund, E. W. Cochran, Z. Shao and J.-P. Tessonnier, Angew. Chem. Int. Ed., 2016, 55, 2368-2373.

15 M. Giurg, E. Kowal, H. Muchalski, L. Syper and J. Młochowski, Synth. Commun., 2009, 39, 251-266

16 V. S. Sobolev, S. T. Deyrup and J. B. Gloer, J. Agr. Food Chem., 2006, 54, 2111 2115.

17 A. Skiba, V. Hecht and D. H. Pieper, J. Bacteriol, 2002, 184, 5402-5409.

18 J. Huo, Z. Hu, D. Chen, S. Luo, Z. Wang, Y. Gao, M. Zhang and H. Chen, ACS Omega, 2017, 2, 5557-5564.

19 P. Fan, H. Lou, W. Yu, D. Ren, B. Ma and M. Ji, Tetrahedron Lett., 2004, 45, 3163-3166.

20 R. Miyano, H. Matsuo, K. Nonaka, T. Mokudai, Y. Niwano, K. Shiomi, Y. Takahashi, S. Ōmura and T. Nakashima, J. Biosci. Bioeng., 2018, 126, 661-666.

21 B. H. Shanks and P. L. Keeling, Green Chem., 2017, 19, 3177-3185.

22 I. Khalil, G. Quintens, T. Junkers and M. Dusselier, Green Chem, 2020, 22, 1517-1541.

23 Y. Deng, L. Ma and Y. Mao, Biochem.Eng. J., 2016, 105, 16-26.

24 N. S. Kruyer and P. Peralta-Yahya, Curr. Opin. Biotech., 2017, 45, 136-143.

25 N.-Z. Xie, H. Liang, R.-B. Huang and P. Xu, Biotechnol. Adv., 2014, 32, 615-622.

26 D. H. Jo, Y. M. Chiou and L. Que Jr., Inorg. Chem., 2001, 40, 3181-3190.

27 R. Yamahara, S. Ogo, H. Masuda and Y. Watanabe, J. Inorg. Biochem., 2002, 88, 284-294.

28 R. Viswanathan, M. Palaniandavar, T. Balasubramanian and T. P. Muthiah, Inorg. Chem., 1998, 37, 2943-2951.

29 W. O. Koch and H. J. Krüger, Angew. Chem. Int. Ed. Engl, 1996, 34, 2671-2674.

30 D. D. Cox and L. Que Jr., J. Am. Chem. Soc., 1988, 110, 8085-8092.

31 R. Jastrzebski, E. J. V. D. Berg, B. M. Weckhuysen and P. C. A. Bruijnincx, Catal. Sci. Technol., 2015, 5, 2103-2109.

32 H. G. Jang, D. D. Cox and L. Que Jr., J. Am. Chem. Soc., 1991, 113, 9200-9204.

33 H. Klenk, P. H. Götz, R. Siegmeier and W. Mayr, in Ullmann's Encyclopedia of Industrial Chemistry, ed. Wiley-VCH, Weinheim, $6^{\text {th }}$ edition, 2005, Peroxy compounds, organic.

34 A. J. Pandell, J. Org. Chem.,1976, 41, 3992-3996.

35 A. J. Pandell, J. Org. Chem., 1983, 48, 3908-3912.

36 Y. Hitomi, H. Yoshida, T. Tanaka and T. Funabiki, J. Mol. Catal. A: Chem., 2006, 251, 239-245.

37 A. J. Pandell and W. E. Matras, J. Org. Chem., 1987, 52, 697-699.

38 X.-B. Zhao, T. Zhang, Y.-J. Zhou and D.-H. Liu, Chin. J. Proc. Eng., 2008, 8, 35-41.

39 A. Wacek, H. Frederiksen, US2534212, 1950.

40 S. Leveneur, M. Thönes, J.-P. Hébert, B. Taouk and T. Salmi, Indus. Eng. Chem. Res., 2012, 51, 13999-14007.

41 B. Guicheret, Y. Bertholo, P. Blach, Y. Raoul, E. Métay and M. Lemaire, ChemSusChem, 2018, 11, 3431-3437.

42 P. D. Filippis, M. Scarsella and N. Verdone, Indus. Eng. Chem. Res., 2009, 48, 1372-1375.

43 E. Santacesaria, V. Russo, R. Tesser, R. Turco and M. D. Serio, Indus. Eng. Chem. Res., 2017, 56, 12940-12952.

44 D. A. Bulushev and J. R. H. Ross, ChemSusChem, 2018, 11, 821-836.

45 J. Bomon, E. V. D. Broeck, M. Bal, Y. Liao, S. Sergeyev, V. V. Speybroeck, B. F. Sels and B. U. W. Maes, Angew. Chem. Int. Ed., 2020, 59, 3063-3068.

46 L. Yang, W. Zhou, K. Seshan and Y. Li, J. Mol. Catal. A: Chem., 2013, 368-369, 61-65.

47 L. Yang, Y. Li and P. E. Savage, Indus. Eng. Chem. Res., 2014, 53, 2633-2639.

48 J. Tian, C. Yi, Z. He, M. Yao and D. Sang, ChemistrySelect, 2017, 2, 9211-9214.

49 F. Chen, Y. Tobimatsu, D. Havkin-Frenkel, R. A. Dixon and J. Ralph, PNAS, 2012, 109, 1772-1777.

50 M. L. Stone, E. M. Anderson, K. M. Meek, M. Reed, R. Katahira, F. Chen, R. A Dixon, G. T. Beckham and Y. Román-Leshkov, ACS Sust. Chem. Eng., 2018, 6 11211-11218. 
51 Y. Li, L. Shuai, H. Kim, A. H. Motagamwala, J. K. Mobley, F. Yue, Y. Tobimatsu, D. Havkin-Frenkel, F. Chen, R. A. Dixon, J. S. Luterbacher, J. A. Dumesic and J. Ralph, Sci. Adv., 2018, 4, eaau2968.

52 Y. Tobimatsu, F. Chen, J. Nakashima, L. L. Escamilla-Treviño, L. Jackson, R. A. Dixon and J. Ralph, Plant Cell, 2013, 25, 2587-2600.

53 S. Wang, S. Su, L.-P. Xiao, B. Wang, R.-C. Sun and G. Song, ACS Sust. Chem. Eng., 2020, 8, 7031-7038

54 J.-L. Dubois, Arkema France, WO2013/011226A1, 2013.

55 L. Berg, K. M. Wendt and R. J. Szabados, US 5006205, 1991.

56 K. Rauch, H. Kiefer, D. Hesse, M. Strohmeyer and H. Hohenschutz, BASF Aktiengesellschaft, US 3983010, 1976. 